\title{
Lung diffusing capacity in a hyperbaric environment: assessment by a rebreathing technique
}

\author{
Željko Dujić, Davor Eterović, Pero Denoble, Goran Krstačić, Jadranka Tocilj
}

\begin{abstract}
A rebreathing method was developed for measuring diffusing lung capacity for carbon monoxide $\left(D_{L} C O\right)$ in a hyperbaric environment. Twenty two professional naval divers with normal lung function were included in the study. Significant correlations were found between rebreathing and single breath measurements for $D_{\mathrm{L}} C O(r=0.94 ; p<0.001$; standard error of the estimate $(\mathrm{SEE})=0.66$ ), alveolar volume (VA) $(\mathbf{r}=0.79 ; \mathbf{p}<0.005$; SEE $=0.51), \quad$ and $D_{\mathrm{L}} \mathrm{CO} / \mathrm{VA} \quad(\mathbf{r}=0.83$; p $<0.001$; SEE $=0.11$ ). In 17 divers, rebreathing $D_{L} C O\left(D_{L} C O r b\right)$ was also measured at 20 minutes pre-dive, during the first decompression stop of the dive to $45 \mathrm{~m}$ for 25 minutes, and at 10 minutes post-dive. Compressed air diving was performed in a dry walk-in chamber and the United States Navy decompression table was followed. The pressure induced decrease in the rate of $\mathrm{CO}$ binding to haemoglobin was adjusted to normobaric conditions using a theoretical approach. Also, the presence of venous bubbles post-dive was detected by precordial doppler monitoring. A biphasic change in $D_{L} C O$ was noted: initially, $D_{1} C O$ was increased during the dive ( $<<0.005)$; this was followed by a post-dive decrease; $D_{L} C O / V A$ changed in a similar manner, as VA was only slightly altered. Only a small post-dive precordial doppler bubble grade was found. In
\end{abstract}

Department of Physiology, Zagreb University School of Medicine in Split, 58000 Split, IL. Ribara 4, Republic of Croatia

Z Dujić

Department of Nuclear Medicine, Clinical Hospital Split, Split, Republic of Croatia

D Eterović

Naval Medical Institute, Split, Republic of Croatia

P Denoble

Department of Internal Medicine, Army Hospital Split, Split, Republic of Croatia

G Krstačić

Pulmonary Division, Clinical Hospital Split, Republic of Croatia

J Tocilj conclusion, rebreathing $D_{L} C O$ measurement is a useful respiratory function test in the hyperbaric environment. It appears that an increase in $D_{L} C O$ during the compressed air dive is related predominantly to increased pulmonary capillary blood volume caused by increased negativity of the pleural pressure, hyperoxic pulmonary vasodilatation, and cardiorespiratory centralisation of the blood. The decrease in $D_{L} C O$ post-dive was only partially related to the presence of the venous bubbles detectable by doppler.

Diffusing lung capacity for carbon monoxide $\left(\mathrm{D}_{\mathrm{L}} \mathrm{CO}\right)$ is presently measured by three methods-namely, the standard single breath method and the less frequently used steady state and rebreathing methods. For steady state and single breath methods the subject has to be sufficiently mobile to attend the respiratory laboratory. Also, it is not possible for some patients to perform the single breath measurement because they cannot hold their breath for 10 seconds, or they have a vital capacity smaller than $1.31 .{ }^{1}$ Clark $e a^{2}$ developed a bedside rebreathing technique predominantly for patients with pulmonary haemorrhagic oedema. Russell et $\mathrm{al}^{3}$ assessed this technique in normal subjects and in patients with various lung diseases.

In the present study we used the rebreathing method in normal professional divers and compared the results with the single breath method. Then we carried out rebreathing $\mathrm{D}_{\mathrm{L}} \mathrm{CO}$ measurement in a hyperbaric environment and developed a theoretical adjustment of those measurements for the rate of $\mathrm{CO}$ binding to haemoglobin $(\mathrm{Hb})$ under normobaric conditions.

\section{Methods}

Twenty two professional navy divers took part in the study. They had normal pulmonary function (table 1), electrocardiogram (ECG), and chest $x$ ray films. Eight of these divers were current smokers (one heavy, three medium heavy, and four light).

The pulmonary function tests were composed of spirometry (forced vital capacity (FVC); forced 
Table 1 Details of divers

\begin{tabular}{|c|c|c|}
\hline & $\operatorname{Mean}(n=22)(S D)$ & Range \\
\hline 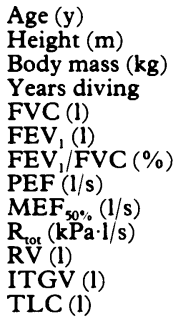 & $\begin{array}{l}28 \cdot 6(6 \cdot 8) \\
1.77(0 \cdot 064) \\
79 \cdot 6(8 \cdot 3) \\
9 \cdot 2(6 \cdot 3) \\
5 \cdot 9(0 \cdot 8) \\
5 \cdot 1(1 \cdot 1) \\
87 \cdot 2(12 \cdot 3) \\
12.0(3 \cdot 3) \\
6.9(2 \cdot 7) \\
0.31(0 \cdot 11) \\
1 \cdot 7(0 \cdot 7) \\
3 \cdot 7(0 \cdot 7) \\
7 \cdot 8(1.4)\end{array}$ & $\begin{array}{c}20-44 \\
1 \cdot 70-191 \\
71-102 \\
3-23 \\
4 \cdot 1-7 \cdot 4 \\
3 \cdot 6-6 \cdot 8 \\
74-112 \\
7 \cdot 3-16 \cdot 8 \\
3 \cdot 4-9 \cdot 7 \\
0 \cdot 13-0 \cdot 62 \\
0 \cdot 5-2 \cdot 8 \\
2 \cdot 3-5 \cdot 2 \\
6 \cdot 5-9 \cdot 6\end{array}$ \\
\hline
\end{tabular}

expiratory volume in one second $\left(\mathrm{FEV}_{1}\right)$; flow volume curve (peak expiratory flow (PEF); maximal expiratory flow rate when $50 \%$ FVC remains $\left(\mathrm{MEF}_{50}\right)$; body plethysmography (total airway resistance (Rtot); intrathoracic gas volume (ITGV); total lung capacity (TLC) (Jaeger MASTERLAB, Germany); single breath diffusing lung capacity for carbon monoxide $\left(\mathrm{D}_{\mathrm{L}} \mathrm{COsb}\right)$; and rebreathing $\mathrm{D}_{\mathrm{L}} \mathrm{CO}$ $\left(\mathrm{D}_{\mathrm{L}} \mathrm{COrb}\right)$ (Morgan MK-4, UK)). The best of triplicate manoeuvres for spirometry, flow volume, and body plethysmography were used. Measurement of $\mathrm{D}_{\mathrm{L}} \mathrm{COrb}$ was by the modified method of Clark et al. ${ }^{2}$ The instrumentation for this method is very simple. It is composed of an anaesthetic bag (1 litre) with a two way breathing valve connected to one end of the bag, and a two way tap connected to the other end. The bag was emptied with a vacuum pump (Morgan MK-4, UK) and filled with 0.751 of the same gas mixture used in single breath measurements $(14 \%$ $\mathrm{He}, 0.3 \% \mathrm{CO}, 21 \% \mathrm{O}_{2}$, and balanced $\mathrm{N}_{2}$ ). With applied nose clip, the patient breathed quietly through the open valve. At the end of normal expiration the two way valve was turned on and the subject started to breathe in and out of the bag, emptying it with each inspiration, at a rate of 10 breaths in 10 seconds, guided by a metronome. After the test was completed, the valve was turned off and the mixture in the bag was analysed for $\mathrm{He}, \mathrm{CO}$, and $\mathrm{O}_{2}$ concentrations.

Krogh's equation for estimation of $\mathrm{D}_{\mathrm{L}} \mathrm{CO} / \mathrm{VA}$ $(\mathrm{mmol} / \mathrm{min} \cdot \mathrm{kPa} \cdot \mathrm{l})$ was used. ${ }^{4}$ For completeness and because of considerable ambiguity of published constants and units we first derived this basic relation for $\mathrm{D}_{\mathrm{L}} \mathrm{CO}$ determination by a rebreathing technique.

\section{DERIVATION OF KROGH'S EQUATION}

The quantity of $\mathrm{CO}$ in mmol present in the lungs at the time $t$ is denoted by $q(t)$. It decreases in time only due to the loss to the capillary sink by diffusion, which is guaranteed by the conditions of the experiment (the subject breathing in a closed system). The quantity of $\mathrm{CO}$ in mmol that crosses the alveocapillary membrane in 1 minute if the driving pressure gradient is $1 \mathrm{kPa}$ is denoted as $\mathrm{D}_{\mathbf{L}} \mathrm{CO}(\mathrm{mmol} /$ $\mathrm{kPa} \cdot \mathrm{min})$. Then the quantity of $\mathrm{CO}$ removed from the lungs in the small time interval from $t$ to $t+\Delta t$, when the variable pressure gradient does not change appreciably from $p(t)$, is approximately:

$$
\mathrm{q}=\mathrm{q}(\mathrm{t}+\Delta \mathrm{t})-\mathrm{q}(\mathrm{t})=-\Delta \mathrm{t} \cdot \mathrm{p}(\mathrm{t}) \cdot \mathrm{D}_{\mathrm{L}} \mathrm{CO}
$$

The equation (1) is valid exactly in the limit $\Delta \mathrm{t}$, $\Delta \mathrm{p} \rightarrow 0$ :

$$
\mathrm{dq} / \mathrm{dt}=-\mathrm{p}(\mathrm{t}) \cdot \mathrm{D}_{\mathrm{L}} \mathrm{CO}
$$

Neglecting capillary CO back pressure, $p$ is the alveolar pressure and, according to the ideal gas equation, it is given by:

$$
p(t)=q(t) \cdot R \cdot T / V A
$$

where $R$ is the universal gas constant $(=0.008314$ $\left.\mathrm{kPa} \cdot \mathrm{l} \cdot \mathrm{K}^{-1} \cdot \mathrm{mmol}^{-1}\right), \mathrm{T}$ is the body temperature in degrees Kelvin, ( $310 \mathrm{~K}$ ), and VA is the alveolar volume in litres under BTPS (body temperature and pressure saturated) conditions. Combining (2) and (3) gives:

$$
\mathrm{dq} / \mathrm{dt}=-\mathbf{R} \cdot \mathbf{T} \cdot\left(\mathrm{D}_{\mathrm{L}} \mathrm{CO} / \mathrm{VA}\right) \cdot \mathrm{q}(\mathrm{t})
$$

The solution of the differential equation is:

$$
q(t)=q(0) \cdot \exp \left(-R \cdot T \cdot\left(D_{L} C O / V A\right) \cdot t\right)
$$

where the time 0 is the arbitrary onset of observation. After converting to logarithms and rearranging, (5) is written as:

$$
\mathrm{D}_{\mathrm{L}} \mathrm{CO} / \mathrm{VA}=(1 / \mathrm{R} \cdot \mathrm{T}) \cdot(1 / \mathrm{t}) \cdot \ln (\mathrm{q}(0) / \mathrm{q}(\mathrm{t}))
$$

Specifying the units and inserting the numerical value for $1 / R \cdot T(=0.388 \mathrm{mmol} / \mathrm{kPa} \cdot 1)$ the equation (6) reads:

$$
\begin{gathered}
\mathrm{D}_{\mathrm{L}} \mathrm{CO} / \mathrm{VA}=0.388(\mathrm{mmol} / \mathrm{kPa} \cdot 1) . \\
(1 / \mathrm{t}(\mathrm{min})) \cdot \ln (\mathrm{q}(0) / \mathrm{q}(\mathrm{t}))(\mathrm{mmol} / \mathrm{kPa} \cdot \mathrm{min} \cdot 1)
\end{gathered}
$$

The ratio $q(0) / q(t)$ in (7) can be substituted by the ratio of fractional CO concentrations in the bag at the start and the end of rebreathing respectively ( $\left.F_{\text {Ico }}\right)$ $\mathbf{F}_{\mathrm{ECO}}$ ), multiplied by the dilution factor. The last is measured by the dilution of $\mathrm{He}$ as the ratio of initial and end fractional $\mathrm{He}$ concentrations in the bag $\left(F_{\mathrm{EHe}}: \mathrm{F}_{\mathrm{IHe}}\right)$. With the usual convention of expressing the rebreathing time $t$ in seconds, equation (7) is transformed to:

$$
\begin{aligned}
& \mathrm{D}_{\mathrm{L}} \mathrm{CO}(\mathrm{mmol} / \mathrm{kPa} \cdot \mathrm{mm} \cdot \mathrm{l})= \\
& \quad \ln \left(\frac{\mathrm{F}_{\mathrm{ICO}} \cdot \mathrm{F}_{\mathrm{EHe}}}{\mathrm{F}_{\mathrm{ECO}} \cdot \mathrm{F}_{\mathrm{IHe}}}\right) \cdot \frac{23 \cdot 28 \mathrm{mmol} / \mathrm{kPa} \cdot 1}{\mathrm{t}(\mathrm{s})}
\end{aligned}
$$

Alveolar volume (VA) can be calculated by $\mathrm{He}$ dilution (at the start and at the end of the rebreathing period):

$$
\mathrm{VA}_{\mathrm{BTPS}}(1)=\frac{\mathrm{F}_{\mathrm{IHe}} \cdot 0.751}{\mathrm{~F}_{\mathrm{EHe}}} \cdot 1 \cdot 1
$$

where 0.751 is the bag volume; 1.1 is a correction factor to convert ATPS (ambient temperature and pressure saturated) to BTPS, assuming an ambient 
temperature of $20^{\circ} \mathrm{C}$. It is equal to $\mathrm{V}_{\mathrm{BAG}}+\mathrm{V}_{\mathrm{LUNG}}$. $\mathrm{D}_{\mathrm{L}} \mathrm{CO}(\mathrm{mmol} / \mathrm{min} \cdot \mathrm{kPa})$ was calculated as:

$$
\mathrm{D}_{\mathrm{L}} \mathrm{CO}=\left(\mathrm{D}_{\mathrm{L}} \mathrm{CO} / \mathrm{VA}\right) \cdot \mathrm{VA}
$$

All subjects performed duplicate $\mathrm{D}_{\mathrm{L}} \mathrm{COsb}$ and $D_{L}$ COrb measurements. The mean of two tests for each method was used.

Adjustment to a standard $\mathrm{Hb}$ concentration of $146 \mathrm{~g} / 1$ was done according to Cotes ${ }^{5}$ :

$\mathrm{D}_{\mathrm{L}} \mathrm{CO}=$ measured $\mathrm{D}_{\mathrm{L}} \mathrm{CO} \cdot \frac{1 \cdot 022+\mathrm{Hb}(\mathrm{g} / \mathrm{l})}{0 \cdot 17 \cdot \mathrm{Hb}(\mathrm{g} / \mathrm{l})}$

ADJUSTMENT TO ATMOSPHERIC $\mathrm{O}_{2}$ PRESSURE (CORRECTION FOR PRESSURE INDUCED DECREASES IN THE RATE OF CO BINDING TO Hb)

It is well known that the rate of $\mathrm{CO}$ binding to $\mathrm{Hb}$ depends on the partial pressure of arterial $\mathrm{O}_{2}$ due to competitive inhibition and the saturation dependent nature of the reaction. This principle is utilised to calculate $\mathrm{D}_{\mathrm{L}} \mathrm{CO}$ membrane $(\mathrm{Dm})$ and its vascular component. The vascular component is the product of the rate of $\mathrm{CO}$ binding to $\mathrm{Hb}(\Theta)$ and the pulmonary capillary blood volume (Vc). As the inverse of $D_{L} C O$ and its components $\mathrm{Dm}$ and $\Theta \cdot V c$ are resistances to diffusion, their relation is governed by the Roughton-Forster equation:

$$
1 / \mathrm{D}_{\mathrm{L}} \mathrm{CO}=1 / \mathrm{Dm}+1 / \Theta \cdot \mathrm{Vc}
$$

The divers breathed the higher tension $\mathrm{O}_{2}$ that produced higher $\mathrm{Hb}$ saturation, resulting in a decrease in the rate of $\mathrm{CO}$ binding to $\mathrm{Hb}$ and thus the decrease in $\mathrm{D}_{1} \mathrm{CO}$ given in (12). To resolve other physiological effects of the hyperbaric environment that increase $\mathrm{D}_{\mathrm{L}} \mathrm{CO}$, as discussed later, it is necessary to convert the $\mathrm{D}_{\mathrm{L}} \mathrm{CO}$ values obtained in the hyperbaric chamber to the ones that would have been obtained if nothing but $\Theta$ had changed from normobaric conditions. This means that $\mathrm{D}_{\mathrm{L}} \mathrm{CO}$ $\left(\Theta_{\text {hyperbaric }}, \mathrm{Dm}, \mathrm{Vc}\right)$ and $\mathrm{D}_{\mathrm{L}} \mathrm{CO}\left(\Theta_{\text {normobaric }}, \mathrm{Dm}, \mathrm{Vc}\right)$ should be related. From (12) a simple algebraic manoeuvre gives the following ratio:

$$
\begin{aligned}
& \mathrm{D}_{\mathrm{L}} \mathrm{CO}\left(\Theta_{\text {normobaric }}, \mathrm{Dm}, \mathrm{Vc}\right)= \\
& \mathrm{D}_{\mathrm{L}} \mathrm{CO}\left(\Theta_{\text {hyperbaric }}, \mathrm{Dm}, \mathrm{Vc}\right) \cdot \\
& \frac{\Theta_{\text {normobaric }}}{\Theta_{\text {hyperbaric }}} \cdot \frac{1+(\mathrm{Vc} / \mathrm{Dm}) \cdot \Theta_{\text {hyperbaric }}}{1+(\mathrm{Vc} / \mathrm{Dm}) \cdot \Theta_{\text {normobaric }}}
\end{aligned}
$$

The rates $\Theta_{\text {normobaric }}$ and $\Theta_{\text {hyperbaric }}$ can be assessed from $\mathrm{PAO}_{2}$ using the equation of Bates et al ${ }^{11}$ (converting the original units: $\mathrm{mm} \mathrm{Hg}$ to $\mathrm{kPa} ; \mathrm{ml} \mathrm{CO}$ (STPD) to $\mathrm{mmol}$ ):

$$
\begin{aligned}
1 / \Theta_{\text {normobaric }}(\mathrm{kPa} \cdot \mathrm{min} \cdot \mathrm{ml} / \mathrm{mmol})= \\
0 \cdot 13 \cdot \mathrm{PAO}_{2 \text { normobaric }}(\mathrm{kPa})+2 \cdot 23 \\
1 / \Theta_{\text {hyperbaric }}(\mathrm{kPa} \cdot \mathrm{min} \cdot \mathrm{ml} / \mathrm{mmol})= \\
0 \cdot 13 \cdot \mathrm{PAO}_{2 \text { hyperbaric }}(\mathrm{kPa})+2 \cdot 23
\end{aligned}
$$

Finally, the ratio $\mathrm{Vc} / \mathrm{Dm}$ in (13) may be measured outside the chamber, or, in normal subjects, approximated as the constant value $4.5 \mathrm{ml} \cdot \mathrm{kPa} \cdot \mathrm{min} /$ mmol. In our calculations we measured the ratios $\mathrm{Vc} /$ $\mathrm{Dm}$ in all divers, as detailed further. $\mathrm{PAO}_{2 \text { normobaric }}$ was measured pre-dive by multiplying the fractional $\mathrm{O}_{2}$ concentration by atmospheric pressure $(101.3 \mathrm{kPa})$, and $\mathrm{PAO}_{2}$ hyperbaric was obtained by multiplying fractional $\mathrm{O}_{2}$, measured during the first decompression stop, by the corresponding pressure $(1 \cdot 6 \cdot 101 \cdot 3 \mathrm{kPa})$. Because fractional concentrations were involved in the last, measurements outside the chamber apply equally to intrachamber values.

In the first part of the study, correlation between the single breath and rebreathing methods was assessed in the sample of 22 divers. In all subjects the duplicate $D_{L}$ COrb test was performed, followed by the duplicate $\mathrm{D}_{\mathrm{L}}$ COsb test one hour later.

The second part of the study had the following protocol: the subjects were exposed to absolute air pressure of 5.5 bar for 25 minutes in a three compartment recompression chamber (Draeger, Germany) and the standard United States Navy decompression table was used; ${ }^{6}$ decompression was carried out with air at two decompression stops (first decompression stop for four minutes at $6 \mathrm{~m}$ and the second decompression stop for 17 minutes at $3 \mathrm{~m}$ ). The $\mathrm{D}_{\mathrm{L}} \mathrm{COrb}$ was measured three times: the first measurement, which included duplicate $\mathrm{D}_{2} \mathrm{CO}, \mathrm{Dm}$, and Vc measurements, was performed 20 minutes pre-dive, followed by the second one during the first decompression stop as the single measurement and the third one in duplicate at 10 minutes post-dive. During dives the subjects were seated upright. As our recompression chamber has three compartments, the person performing the rebreathing test was able to enter and leave the main compartment during the first decompression stop.

Venous bubbles were detected precordially with a doppler bubble detector (Sodelec SA, France) for one minute at rest and during 10 consecutive cardiac cycles with the diver performing deep knee bends (squatting down slowly and then rising to an upright position (repeated twice), using the Kisman-Masurel code. ${ }^{7}$ Precordial bubble grade was monitored at 10 minutes post-dive.

For comparison of the pre-dive, dive, and postdive $D_{L}$ COrb, $D_{L} C O / V A r b$, and VArb values paired $t$ tests were used. For correlation of the rebreathing and the single breath values least squares linear regression analysis was applied. All data were expressed as the mean (standard deviation (SD)) and range.

\section{Results}

Table 2 shows the mean values of $\mathrm{D}_{\mathrm{L}} \mathrm{CO}, \mathrm{D}_{\mathrm{L}} \mathrm{CO} / \mathrm{VA}$, and VA measured with rebreathing and single breath methods in 22 professional navy divers. On average $D_{\mathrm{L}}$ COrb was reduced by $28.3 \%$ in comparison with $\mathrm{D}_{\mathrm{L}}$ COsb due to decreased VArb $(27 \cdot 0 \%)$.

Significant correlations were found between 
Table 2 Mean values of $D_{L} C O, D_{L} C O / V A$, and $V A$ measured with rebreathing or single breath methods in 22 divers

\begin{tabular}{lcl}
\hline & Mean $(n=22)$ & \\
& $(S D)$ & Range \\
\hline $\mathrm{D}_{\mathrm{L}} \mathrm{COsb}(\mathrm{mmol} / \mathrm{min} \cdot \mathrm{kPa})$ & $12 \cdot 08(1 \cdot 75)$ & $8 \cdot 4-15 \cdot 6$ \\
$\mathrm{D}_{\mathrm{L}} \mathrm{CO} / \mathrm{VAsb}(\mathrm{mmol} / \mathrm{min} \cdot \mathrm{kPa} \cdot \mathrm{l})$ & $1 \cdot 87(0 \cdot 19)$ & $1 \cdot 65-2 \cdot 45$ \\
$\mathrm{VAsb}(\mathrm{l})$ & $6 \cdot 45(0 \cdot 81)$ & $4 \cdot 8-8 \cdot 3$ \\
$\mathrm{D}_{\mathrm{L}} \mathrm{COrb}(\mathrm{mmol} / \mathrm{min} \cdot \mathrm{kPa})$ & $8 \cdot 66(1 \cdot 28)$ & $6 \cdot 1-10 \cdot 8$ \\
$\mathrm{D}_{\mathrm{L}} \mathrm{CO} / \mathrm{VArb}(\mathrm{mmol} / \mathrm{min} \cdot \mathrm{kPa} \cdot \mathrm{l})$ & $1 \cdot 85(0 \cdot 18)$ & $1 \cdot 62-2 \cdot 32$ \\
VArb (l) & $4 \cdot 70(0 \cdot 69)$ & $3 \cdot 4-5 \cdot 9$ \\
\hline
\end{tabular}

$\mathrm{D}_{\mathrm{L}}$ COsb and $\mathrm{D}_{\mathrm{L}}$ COrb $(\mathrm{r}=0.94 ; \mathrm{p}<0.001$; standard error of the estimate $(\mathrm{SEE})=0.66 \mathrm{mmol} /$ $\mathrm{kPa} \cdot \mathrm{min}$ ) (table 3 and fig 1 ), $\mathrm{D}_{\mathrm{L}} \mathrm{CO} / \mathrm{VAsb}$ and $\mathrm{D}_{\mathrm{L}} \mathrm{CO} /$ VArb $(r=0.83 ; p<0.001 ; \quad S E E=0.11 \mathrm{mmol} /$ $\mathrm{kPa} \cdot \min$ ) (table 3 and fig 2), and VAsb and VArb $(\mathrm{r}=0.79 ; \mathrm{p}<0.005 ; \mathrm{SEE}=0.51 \mathrm{mmol} / \mathrm{kPa} \cdot \mathrm{min})$ (table 3).

Figure 3 shows the effect of a single air dive to $45 \mathrm{~m}$ for 25 minutes on $\mathrm{D}_{\mathrm{L}} \mathrm{CO}$ measured during the first decompression stop at $6 \mathrm{~m}(\mathrm{n}=17)$. By comparison with the pre-dive values intrachamber $D_{L} C O$ increased significantly $(p<0.005)$, whereas it decreased post-dive. The ratio $D_{L} C O / V A r b$ was also increased during the first decompression stop $(p<0.005)$, because VArb was unchanged. All of these statements apply equally to the raw $\mathrm{D}_{\mathrm{L}} \mathrm{CO}$ data as well as to $\mathrm{D}_{\mathrm{L}} \mathrm{CO}$ adjusted to standard $\mathrm{Hb}$ and rate of $\mathrm{CO}$ binding to $\mathrm{Hb}$ (for individual data see table 4). Mean precordial doppler bubble grades at rest and after deep knee bends were $0 \cdot 1$ and $0 \cdot 7$ (grading scale $0-4)$ respectively.

\section{Discussion}

Measurement of diffusing lung capacity is an important clinical test of respiratory function in evaluating the exchange of $\mathrm{O}_{2}$ and $\mathrm{CO}_{2}$ across the blood gas barrier. Because the most frequently used single breath method has certain limitations (patients have to be mobile to attend the respiratory laboratory, to be able to hold their breath for at least 10 seconds, and to have a vital capacity above 1.31$),{ }^{1}$ recent modification of the rebreathing method by Clark $e t$ $a l^{2}$ expanded its use to virtually all patients. Certain assumptions apply to rebreathing $\mathrm{D}_{\mathrm{L}} \mathrm{CO}$ measurement-namely, a negligibly small dead space of subject and equipment; insignificant time spent at end expiration in relation to the time spent at full inspiration making the bag extension of the lung so that alveolar volume is calculated as $\mathrm{V}_{\mathrm{BAG}}+\mathrm{V}_{\mathrm{LUNG}}$; and instantaneous and uniform mixing of $\mathrm{CO}$ and $\mathrm{He}^{3}$ Despite this, surprisingly good correlations between $\mathrm{D}_{\mathrm{L}}$ COsb and $\mathrm{D}_{\mathrm{L}}$ COrb, $\mathrm{D}_{\mathrm{L}} \mathrm{CO} /$ VAsb and

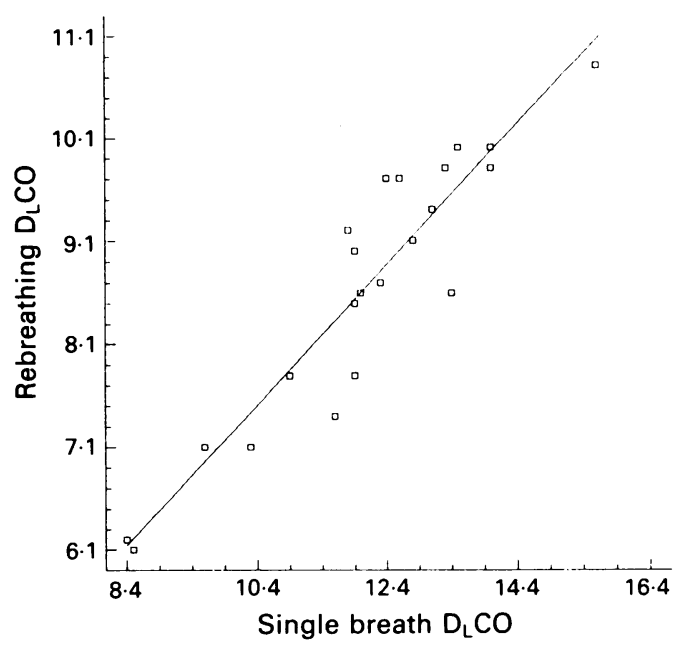

Figure 1 Relation between $D_{L} C O$ values measured by single breath and rebreathing methods $(y=1 \cdot 27 x+1 \cdot 11$; $r=0.94 ; p<0.001 ; S E E=0.66)$ in 22 divers.

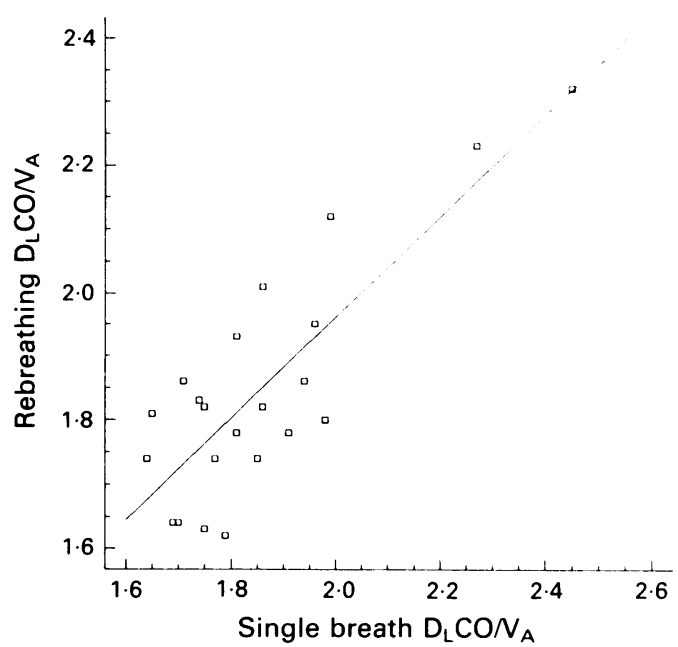

Figure 2 Relation between $D_{L} C O / V A$ values measured by single breath and rebreathing methods $(y=0 \cdot 84 \times+0 \cdot 32$; $r=0.83 ; p<0.001 ; S E E=0.11)$ in 22 divers.

Table 3 Correlations between $D_{\iota} C O, D_{\iota} C O / V A$, and VA measured with rebreathing or single breath methods in 22 divers

\begin{tabular}{|c|c|c|c|c|}
\hline Variable & Equation & $r$ & p Value & $S E E$ \\
\hline $\begin{array}{l}\mathrm{D}_{\mathrm{L}} \mathrm{CO} \\
\mathrm{D}_{\mathrm{L}} \mathrm{CO} / \mathrm{VA} \\
\mathrm{VA}\end{array}$ & $\begin{array}{l}\mathrm{D}_{\mathrm{L}} \mathrm{COrb}=1 \cdot 27 \cdot \mathrm{D}_{\mathrm{L}} \mathrm{COsb}+1 \cdot 11 \\
\mathrm{D}_{\mathrm{L}} \mathrm{CO} / \mathrm{VArb}=0 \cdot 84 \cdot \mathrm{D}_{\mathrm{L}} \mathrm{CO} / \mathrm{VAsb}+0 \cdot 32 \\
\text { VArb }=0 \cdot 93 \cdot \mathrm{VAsb}+2 \cdot 09\end{array}$ & $\begin{array}{l}0.94 \\
0 \cdot 83 \\
0 \cdot 79\end{array}$ & $\begin{array}{l}<0.001 \\
<0.001 \\
<0.005\end{array}$ & $\begin{array}{l}0.66 \\
0.11 \\
0.51\end{array}$ \\
\hline
\end{tabular}




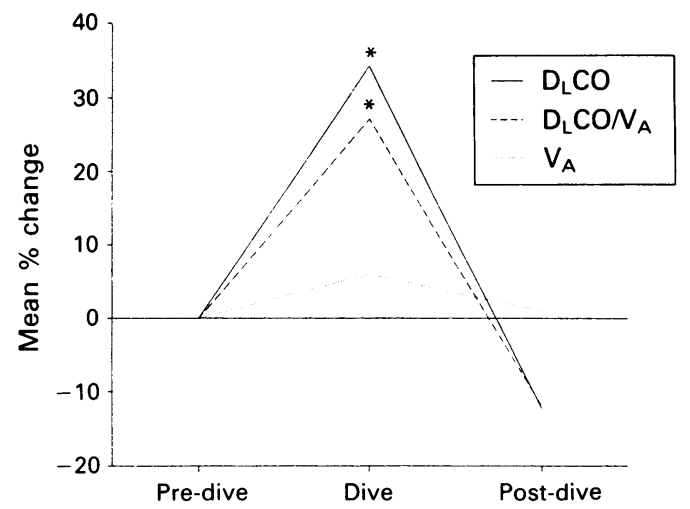

Figure 3 Mean \% change of $D_{L} C O, D_{L} C O / V A$, and VA measured with rebreathing technique before, during, and after a single air dive to $45 \mathrm{~m}$ for 25 minutes in 17 divers. ${ }^{\star} p<0.005$.

$\mathrm{D}_{\mathrm{L}} \mathrm{CO} / \mathrm{VArb}$, and VAsb and VArb were found in the present study, in accord with reports of other investigators. ${ }^{23}$

The simplicity of the method and mobility of the rebreathing equipment allowed us to measure $D_{L} C O$ in the hyperbaric environment, to our knowledge, for the first time. It was measured before, during, and after the compressed air dive to $45 \mathrm{~m}$ for 25 minutes in the walk-in recompression chamber. A significant increase in $\mathrm{D}_{\mathrm{L}}$ COrb was found during the dive at a depth of $6 \mathrm{~m}$, followed by a post-dive decrease (fig 3 ). Possible explanations for this effect of the hyperbaric environment on $\mathrm{D}_{\mathrm{L}} \mathrm{CO}$ are: (1) a pressure proportional increase of air density and consequent increased airway resistance increases respiratory muscle activity. This results in increased negativity of the pleural pressure that facilitates the venous return, finally causing enlargement of the pulmonary capillary blood volume; (2) breathing hyperbaric air increases the total amount of $\mathrm{O}_{2}$ predominantly through solutions in plasma and the increased amount of oxygen is available to the peripheral tissues. By autoregulation this causes local vasoconstriction $^{8}$ and redistribution of the blood to the central cardiorespiratory region. Quantitative support for this idea is given by Fagraeus et al. ${ }^{9}$ They reported that during compressed air diving the mean arterial pressure was unchanged in the presence of bradycardia. To maintain the mean arterial pressure the stroke volume should have been increased. The sole reason for this must be increased diastolic filling, accomplished by centralisation of the blood caused by peripheral vasoconstriction. The last was not caused by sympathetic nervous system activity, as bradycardia occurred and blood noradrenaline concentration was decreased. ${ }^{9}$ Therefore it appears that the centralisation of hyperoxic blood volume augments diastolic filling and the capillary blood volume considerably; (3) pulmonary blood vessels responded to hyperoxia with vasodilatation; (4) alveolar volume was found to be increased in the present study during the single air dive compared with pre-dive values, although this was a minor contribution; and (5) decrease in the rate of $\mathrm{CO}$ binding to $\mathrm{Hb}(\Theta)$ in a hyperoxic environment has the opposite effect of decreasing $\mathrm{D}_{\mathrm{L}} \mathrm{CO}$. This effect can be assessed by in vitro measurement as the sole function of $\mathrm{PO}_{2}$ and thus presumably does not exhibit intraindividual variations. Therefore we found it advantageous to adjust intrachamber $D_{L} C O$ values to normobaric $\Theta$.

Table 4 Individual data for 17 divers

\begin{tabular}{|c|c|c|c|c|c|c|c|c|c|}
\hline \multirow[b]{2}{*}{ Diver } & \multicolumn{3}{|c|}{$D_{L} C O(\mathrm{mmol} / \mathrm{kPa} \cdot \mathrm{min})$} & \multicolumn{3}{|c|}{$D_{L} C O / V A(\operatorname{mmol} / k P a \cdot \min \cdot l)$} & \multicolumn{3}{|l|}{$V A(l)$} \\
\hline & Pre-dive & Intrachamber & Post-dive & Pre-dive & Intrachamber & Post-dive & Pre-dive & Intrachamber & Post-dive \\
\hline $\begin{array}{r}1 \\
2 \\
3 \\
4 \\
5 \\
6 \\
7 \\
8 \\
9 \\
10 \\
11 \\
12 \\
13 \\
14 \\
15 \\
16 \\
17 \\
\bar{x} \\
\text { SD }\end{array}$ & $\begin{array}{l}5 \cdot 8 \\
6 \cdot 3 \\
5 \cdot 9 \\
6 \cdot 1 \\
4 \cdot 8 \\
6 \cdot 2 \\
7 \cdot 0 \\
8 \cdot 8 \\
7 \cdot 0 \\
8 \cdot 2 \\
7 \cdot 3 \\
9 \cdot 0 \\
9 \cdot 2 \\
7 \cdot 0 \\
7 \cdot 4 \\
7 \cdot 4 \\
9 \cdot 9 \\
7 \cdot 3 \\
1 \cdot 4\end{array}$ & $\begin{array}{c}8 \cdot 6(7 \cdot 6) \\
10 \cdot 6(9 \cdot 3) \\
8 \cdot 0(7 \cdot 2) \\
8 \cdot 3(7 \cdot 4) \\
6 \cdot 9(6 \cdot 1) \\
9 \cdot 4(8 \cdot 4) \\
10 \cdot 5(9 \cdot 2) \\
11 \cdot 1(9 \cdot 8) \\
11 \cdot 3(10 \cdot 2) \\
9 \cdot 6(8 \cdot 7) \\
11 \cdot 0(9 \cdot 8) \\
11 \cdot 1(10 \cdot 1) \\
12 \cdot 1(10 \cdot 7) \\
8 \cdot 4(7 \cdot 5) \\
9 \cdot 0(8 \cdot 1) \\
8 \cdot 2(7 \cdot 1) \\
12 \cdot 8(11 \cdot 3) \\
9 \cdot 8 \\
1.6\end{array}$ & $\begin{array}{r}5 \cdot 4 \\
5 \cdot 7 \\
5 \cdot 5 \\
5 \cdot 1 \\
4 \cdot 5 \\
5 \cdot 7 \\
5 \cdot 9 \\
8 \cdot 0 \\
6 \cdot 5 \\
5 \cdot 7 \\
6 \cdot 3 \\
6 \cdot 6 \\
7 \cdot 9 \\
6 \cdot 4 \\
5 \cdot 9 \\
6 \cdot 7 \\
10.0 \\
6.4 \\
1.3\end{array}$ & $\begin{array}{l}1.35 \\
1.44 \\
1.41 \\
1.48 \\
1.56 \\
1.40 \\
1.50 \\
1.73 \\
1.70 \\
1.49 \\
1.40 \\
2.00 \\
1.74 \\
2.12 \\
1.96 \\
1.61 \\
2.32 \\
1.66 \\
0.27\end{array}$ & $\begin{array}{l}2.26(2.00) \\
2.12(1.86) \\
1.60(1.43) \\
1.66(1.48) \\
1.97(1.74) \\
2.23(2.01) \\
2.06(1.81) \\
2.41(2.13) \\
2.51(2.26) \\
1.88(1.70) \\
1.86(1.66) \\
2.22(2.02) \\
2.09(1.85) \\
2.10(1.85) \\
1.96(1.78) \\
2.05(1.77) \\
2.84(2.50) \\
2.11 \\
0.30\end{array}$ & $\begin{array}{l}1.32 \\
1.21 \\
1.17 \\
1.21 \\
1.55 \\
1.04 \\
1.09 \\
1.86 \\
1.48 \\
1.19 \\
1.43 \\
1.65 \\
1.46 \\
2.00 \\
1.31 \\
1.56 \\
2.22 \\
1.46 \\
0.33\end{array}$ & $\begin{array}{l}4 \cdot 3 \\
4 \cdot 4 \\
4 \cdot 2 \\
4 \cdot 1 \\
3 \cdot 1 \\
4 \cdot 4 \\
4 \cdot 7 \\
5 \cdot 1 \\
4 \cdot 1 \\
5 \cdot 5 \\
5 \cdot 2 \\
4 \cdot 5 \\
5 \cdot 3 \\
3 \cdot 3 \\
3 \cdot 8 \\
4 \cdot 6 \\
4 \cdot 3 \\
4 \cdot 4 \\
0 \cdot 6\end{array}$ & $\begin{array}{l}3 \cdot 8 \\
5 \cdot 0 \\
5 \cdot 0 \\
5 \cdot 0 \\
3 \cdot 5 \\
4 \cdot 2 \\
5 \cdot 1 \\
4 \cdot 6 \\
4 \cdot 5 \\
5 \cdot 1 \\
5 \cdot 9 \\
5 \cdot 0 \\
5 \cdot 8 \\
4 \cdot 0 \\
4 \cdot 6 \\
4 \cdot 0 \\
4 \cdot 5 \\
4 \cdot 7 \\
0 \cdot 7\end{array}$ & $\begin{array}{l}4 \cdot 1 \\
4 \cdot 7 \\
4 \cdot 7 \\
4 \cdot 2 \\
2 \cdot 9 \\
5 \cdot 5 \\
5 \cdot 4 \\
4 \cdot 3 \\
4 \cdot 4 \\
4 \cdot 8 \\
4 \cdot 4 \\
4 \cdot 0 \\
5 \cdot 4 \\
3 \cdot 2 \\
4 \cdot 5 \\
4 \cdot 3 \\
4 \cdot 5 \\
4 \cdot 4 \\
0 \cdot 7\end{array}$ \\
\hline
\end{tabular}

$\mathrm{D}_{\mathrm{L}} \mathrm{CO}$ and $\mathrm{D}_{2} \mathrm{CO} / \mathrm{VA}$ intrachamber values are reported adjusted to standard $\mathrm{Hb}$ and for standard rate of $\mathrm{CO}$ binding for $\mathrm{Hb}$. The raw data are given in parentheses; pre-dive and post-dive values are reported adjusted to standard $\mathrm{Hb}$. 
By the removal of this calculable variable, it is possible to appreciate more thoroughly the impact of other physiological parameters on changes of $\mathrm{D}_{\mathrm{x}} \mathrm{CO}$ in hyperbaria. In our conditions (6 m depth) measured $\mathrm{D}_{\mathrm{r}} \mathrm{CO}$ values were adjusted to normobaric $\Theta$ by multiplying by $1 \cdot 12$. At greater depths, however, this correction may become quite large (for instance, at $50 \mathrm{~m}$ it equals $1 \cdot 84$ ).

Diffusing lung capacity is dependent on the perfusion of the pulmonary capillary bed, the thickness of the alveolocapillary membrane, the surface area of the membrane, and the diffusion coefficient of the gas in the membrane. It appears that the observed increase of $\mathrm{D}_{\mathrm{L}} \mathrm{CO}(+34 \%)$ in the hyperbaric environment is probably a result of greatly increased pulmonary capillary blood volume, which expands the capillaries and increases the surface through which gases can diffuse in the blood. Another minor contribution is an increase in the alveolar volume $(+6 \%)$, which expands the surface area of the respiratory membrane.

In the present study a decrease in $\mathrm{D}_{\mathrm{L}} \mathrm{CO}$ was found after the single air dive to $45 \mathrm{~m}$ for 25 minutes (fig 3). At the same time the precordial doppler bubble grade was small. The possible explanations for this discrepancy between $\mathrm{D}_{\mathrm{L}} \mathrm{CO}$ (quantitative parameter) and precordial bubble grade (semiquantitative parameter) are (1) doppler has limited sensitivity to venous bubbles with radius smaller than $50 \mu \mathrm{m},{ }^{10}$ whereas $D_{L} C O$ is a method which measures the gas exchange in the pulmonary capillaries with radius of about $8 \mu \mathrm{m}$; (2) bubble grade is an index of an instant rate of production of the bubbles, whereas $D_{L} C O$ shows the net effect of integrated production and elimination, up to the time considered; and (3) bubble grade may not be at its maximum at that time (10 minutes post-dive). The mechanism of post-dive $\mathrm{D}_{\mathrm{L}} \mathrm{CO}$ reduction is that trapped venous bubbles in the pulmonary circulation decrease the effective vascular surface area and volume with resulting impaired gas exchange.
In conclusion, we applied the rebreathing method for measurement of diffusing lung capacity in the hyperbaric environment. It appears that the increase in diffusing lung capacity during the compressed air dive was predominantly caused by increased pulmonary capillary blood volume, and the change in alveolar volume was not important. The decrease in $\mathrm{D}_{\mathrm{t}} \mathrm{CO}$ after the dive was only partially caused by the venous bubbles detected by precordial doppler monitoring.

Requests for reprints to: Željko Dujić $\mathrm{MD}, \mathrm{PhD}$, Department of Physiology, Zagreb University School of Medicine in Split, 58000 Split, I L Ribara 4, Republic of Croatia.

1 Ogilvie CM, Forster RE, Blakemore WS, Morton JW. A standardised breath-holding technique for the clinical measurement of the diffusing capacity of the lung for carbon monoxide. J Clin Invest 1957;36:1-17.

2 Clark EH, Jones HA, Hughes JMB. Bedside rebreathing technique for measuring carbon monoxide uptake by the lung. Lancet 1978;i:791-3.

3 Russell NJ, Bagg LR, Dobrzynski J, Hughes DTD. Clinical assessment of a rebreathing method for measuring pulmonary gas transfer. Thorax 1983;38:212-5.

$4 \mathrm{Krogh} M$. The diffusion of gases through the lungs of man. $J$ Physiol 1914/15;49:271-300.

5 Cotes JE. Lung function. 4th ed. London: Blackwell Scientific Publications, 1979:249.

6 US Navy Diving Manual. Navy standard air decompression table. Washington: Government printing office, 1973. (NAVSHIPS 0994-001-9010).

7 Guillerm R, Masurel G. Le detection ultrasonore a effet Doppler de bulles circulantes. Medicine Subaquatique et Hyperbare 1982;1:33-44.

8 Guyton AC, Granger HJ, Coleman TG. Autoregulation of the total systemic circulation and its relation to control of cardiac output and arterial pressure. Circ Res 1971;28 (supp 1): 93-102.

9 Fagraeus L, Haggendal J, Linarsson D. Heart rate, arterial blood pressure and noradrenaline levels during exercise with hyperbaric oxygen and nitrogen. Fowars Medizin 1973;9:265-70.

10 Nishi RY. Ultrasonic detection of bubbles with Doppler flow transducers. Ultrasonics 1972;10:173-9.

Accepted 19 August 1991 